\title{
Treatment of micropollutants in municipal wastewater: Ozone or powdered activated carbon?
}

\section{Supplementary data}

Jonas Margot $^{\mathrm{a}^{*}}$, Cornelia Kienle ${ }^{\mathrm{b}}$, Anoÿs Magnet ${ }^{\mathrm{c}}$, Mirco Weil ${ }^{\mathrm{d}}$, Luca Rossi ${ }^{\mathrm{a}}$, Luiz Felippe de Alencastro $^{\mathrm{a}}$, Christian Abegglen ${ }^{\mathrm{e}}$, Denis Thonney ${ }^{\mathrm{c}}$, Nathalie Chèvre ${ }^{\mathrm{f}}$, Michael Schärer ${ }^{\mathrm{g}}$, D. A. Barry $^{\mathrm{a}}$

${ }^{a}$ School of Architecture, Civil and Environmental Engineering (ENAC), Ecole Polytechnique Fédérale de Lausanne (EPFL), Station 2, 1015 Lausanne,Switzerland (jonas.margot@epfl.ch, luca.rossi@epfl.ch, felippe.dealencastro@epfl.ch,andrew.barry@epfl.ch)

${ }^{\mathrm{b}}$ Swiss Centre for Applied Ecotoxicology, Eawag/EPFL, Überlandstrasse 133, 8600 Dübendorf, Switzerland (cornelia.kienle@oekotoxzentrum.ch)

${ }^{\mathrm{c}}$ Sanitation Service, City of Lausanne, Rue des terreaux 33, 1002 Lausanne, Switzerland (anoys.magnet@lausanne.ch, denis.thonney@sige.ch)

${ }^{\mathrm{d}}$ ECT Oekotoxikologie GmbH, Boettgerstrasse 2-14, 65439 Floersheim/Main, Germany (m.weil@ect.de)

e Swiss Federal Institute of Aquatic Science and Technology (Eawag), Überlandstrasse 133, 8600 Dübendorf, Switzerland (christian.abegglen@vsa.ch)

${ }^{\mathrm{f}}$ Faculty of Geosciences and the Environment, University of Lausanne, 1015 Lausanne, Switzerland (nathalie.chevre@ unil.ch)

${ }^{\mathrm{g}}$ Federal Office for the Environment (FOEN), Water Division, 3003 Bern, Switzerland (michael.schaerer@bafu.admin.ch)

* Corresponding author:

Jonas Margot, jonas.margot@epfl.ch, Ph: +41 (21) 693-8086, Fax: +41 (21) 693-8035, Address: EPFL ENAC IIE ECOL, Station 2, 1015 Lausanne, Switzerland 


\section{Table of contents}

Materials and methods - complementary information

Table S1: Physico-chemical properties of the micropollutants routinely analysed

Table S2: Procedure for sample preparation for analysis of estrogens and bioassay enrichment 6

Table S3: Specification for LC-MS/MS analytics of estrogenic active substances 7

Figure S1: Influence of dilution by runoff water on the concentration of selected pesticides in raw wastewater

Figure S2: Removal efficiency of 40 to 43 micropollutants during conventional WWTPs, ozonation and PAC-UF treatment

Figure S3: Removal of 18 micropollutants in the biological treatment as a function of the level of nitrification

Table S4: Correlation coefficients between the removal of 42 micropollutants and the level of nitrification 11

Figure S4: Removal of fluoroquinolone antibiotics by ozonation as a function of $p H \ldots \ldots . . .12$

Figure S5: Ozone dosage as a function of DOC and $\mathrm{NO}_{2}$ concentrations

Figure S6: Influence of the ozone dose on the removal of 15 micropollutants by ozonation

Figure S7: Effect of the sand filter on the removal of micropollutants after ozonation _...... 14

Figure S8: Influence of the ozone dose on bromate formation 15

Figure S9: Influence of DOC on PAC removal of five micropollutants 16

Figure S10: Estrogenic activity removal in the biological treatment as a function of the level of nitrification 17

Figure S11: Removal of macropollutants with the advanced treatments 17

Figure S12: Influence of the treatments on the concentration of indicator bacteria 18 


\section{Materials and methods - complementary information}

\section{Analyses of micropollutants - Synthesis of the analytical method}

Upon arrival in the laboratory, samples were immediately acidified to $\mathrm{pH} 2.5$ with $5 \mathrm{~N} \mathrm{HCl}$ and filtered at $0.7 \mu \mathrm{m}$ through glass fibre filters (type GF/F, Whatman). Analysis of 58 hydrophilic micropollutants (36 pharmaceuticals, 13 biocides and pesticides, 2 corrosion inhibitors and 7 endocrine compounds, Table S1), were conducted on the filtrate as described by Morasch et al. (2010). The target compounds were extracted less than $1 \mathrm{~h}$ after acidification by an automated solid phase extraction (SPE) system (GX-274 ASPEC, Gilson, USA) on hand-assembled two-layered cartridges (Oasis HLB and mixture of Strata X-CW, Strata X-AW and Isolute ENV+ phases). The eluent was then analysed by ultra-performance liquid chromatography (UPLC) (Acquity UPLC system, with HSS T3 or BEH C18 column depending of the compounds, from Waters, USA) coupled to a tandem quadrupole mass spectrometer (MS/MS) (Acquity TQ Detector, Waters). To account for losses during SPE and the matrix effect, samples were spiked with deuterated surrogates, as described by Morasch et al. (2010). UPLC-MS/MS conditions, extraction efficiency of the associated deuterated standards and repeatability of the method are detailed by Morasch et al. (2010).

\section{Yeast Estrogen Screen (YES) - Synthesis of the method}

The yeast estrogen screen with the recombinant yeast Saccharomyces cerevisiae was performed according to Routledge and Sumpter (1996) in 96-well microtitre plates using yeast cells provided by J. Sumpter (Brunel University, Uxbridge, UK). In brief, yeast cells were cultured in minimal medium on an orbital shaker at $30^{\circ} \mathrm{C}$ for $24 \mathrm{~h}$ before the onset of the test. At the beginning of the test, 1:2 dilution series of the reference substance, the enriched wastewater samples and the solvent control were pipetted onto the plates. The solvent was evaporated completely on a sterile bench. In the meantime the cell density of the yeast cells was determined, and an assay medium prepared (seeded with $4 \times 10^{7}$ yeast cells). Subsequently, the yeast-cell suspension was pipetted on the test plate $(200 \mu \mathrm{l} /$ well $)$. The plate was incubated at $30^{\circ} \mathrm{C}$. After $72 \mathrm{~h}$, cell density $\left(\mathrm{OD}_{620 \mathrm{~nm}}\right)$ and colour change $\left(\mathrm{OD}_{540 \mathrm{~nm}}\right)$ were measured using a plate reader (Synergy 4, Biotek, Winooski, USA).

\section{Combined Algae Assay-Synthesis of the method}

The combined algae assay on the green algae Pseudokirchneriella subcapitata was conducted as described by Escher et al. (2008). The herbicide diuron served as the reference substance and ethanol as the solvent control $(50 \mu \mathrm{l} /$ well, 8 wells/plate). After a complete ablation of the solvent, the samples were re-suspended in 100- $\mu 1$ algae medium. Finally, $100 \mu 1$ of algae suspension with an $\mathrm{OD}_{685}$ of 0.1 were added to each well. Photosynthesis inhibition by means of effective quantum yield was measured after 2 and $24 \mathrm{~h}$ using a Maxi-Imaging PAM (pulse amplitude modulation, IPAM) device (Walz, Effeltrich, Germany) as described by Schreiber et al. (2007). Algae growth was measured by means of absorbance at $685 \mathrm{~nm}$ in a microtitre plate photometer (Synergy 4, Biotek, Winooski, USA) at the test start and end as well as on two occasions in between. The toxicity of the wastewater samples was expressed as diuronequivalent concentrations (DEQs) for the endpoint "inhibition of Photosystem II" and toxic equivalent concentrations (TEQs, virtual baseline toxicant) for growth inhibition (Escher et al., 2008). 
Fish early life stage test with rainbow trout - Synthesis of the method

This test was performed according to OECD guideline 210 (OECD, 1992b). Details of the methodology are described by Stalter et al. (2010). In brief, freshly fertilized eggs $(<1 \mathrm{~h})$ of rainbow trout (Oncorhynchus mykiss) were exposed to the test waters in 8-1 stainless steel vessels in a flow-through system. Reconstituted water (OECD guideline 203, OECD, 1992a) served as the control medium. At the start of the test, 70 eggs/replicate were randomly distributed to the test vessels and gradually reduced to 40 eggs the next day. The fish embryos were exposed at $10 \pm 2^{\circ} \mathrm{C}$ and in darkness. Flow of test media into each test vessel was adjusted to $11 \mathrm{ml} \mathrm{min}^{-1}$, corresponding to two test vessel volume exchanges per day. For the post hatch period the temperature was raised to $12 \pm 2^{\circ} \mathrm{C}$ and a $12 / 12 \mathrm{~h}$ photoperiod was set. Flow-through rates in the test vessels were adjusted weekly depending on the fish developmental stage to reach $44 \mathrm{ml} \mathrm{min}{ }^{-1}$ seven days before the test end, achieving a eightfold medium exchange in the test vessels per day (OECD, 1992b). From the beginning of swim-up onwards, the fish were fed four times per day (trout starter, $4 \%$ body weight per day). In total four control and three replicate treatments for all wastewaters were assessed. During the test period several endpoints were determined daily, namely: hatching, mortality, swim up, malformations and abnormal behaviour. After the end of the test fish were humanely killed with an overdose of MS222 (tricaine methanesulfonate, Sigma-Aldrich, St. Louis, USA). Afterwards individual fish were blotted dry and fresh weight and length were measured. The plasma vitellogenin concentration was determined in whole body homogenates of 20 fish per control and wastewater as described by Holbech et al. (2006) using a vitellogenin ELISA test kit for rainbow trout (Biosense, Bergen, Norway) in a 1:20 dilution. 
Table S1. Physico-chemical properties of the 58 micropollutants routinely analysed.

\begin{tabular}{|c|c|c|c|c|c|c|c|}
\hline Compound & CAS-No & $\mathrm{M}[\mathrm{g} / \mathrm{mol}]^{\mathrm{a}}$ & $\log _{\text {Kow }}{ }^{a}$ & $\mathrm{pK}_{\mathrm{a}}^{\mathrm{a}}$ & $\begin{array}{c}\text { Charge at } \\
\text { pH } 7^{\mathrm{b}}\end{array}$ & $\begin{array}{c}\log D_{o w} \\
(\mathrm{pH} 7)^{\mathrm{c}}\end{array}$ & Type $^{d}$ \\
\hline \multicolumn{8}{|l|}{ Pharmaceuticals } \\
\hline Acipimox & [51037-30-0] & 154.1 & -0.52 & 3.3 & -1 & -2.1 & A \\
\hline Atenolol & [29122-68-7] & 266.3 & 0.16 & 9.6 & 1 & -1.3 & B \\
\hline Azithromycin & [83905-01-5] & 749 & 4.02 & $8.7 ; 9.5$ & 2 & 2.8 & B \\
\hline Bezafibrate & [41859-67-0] & 361.8 & 4.25 & $3.7 ; 13.6$ & -1 & 2.7 & A \\
\hline Carbamazepine & [298-46-4] & 236.3 & 2.45 & 13.9 & 0 & 2.5 & $\mathrm{~N}$ \\
\hline Ciprofloxacin & [85721-33-1] & 331.4 & 0.28 & $6.1 ; 8.8$ & $1 ; Z ; 0 ;-1$ & 0.3 & $\mathrm{Z}$ \\
\hline Clarithromycin & [81103-11-9] & 748 & 3.16 & 9.0 & 1 & 1.8 & B \\
\hline Clindamycin & [18323-44-9] & 425 & 2.16 & 7.5 & $1 ; 0$ & 1.4 & $\mathrm{~B}$ \\
\hline Clofibric acid & [882-09-7] & 214.7 & 2.57 & 3.5 & -1 & 1.0 & A \\
\hline Diatrizoic acid & [117-96-4] & 613.9 & 1.37 & $1.2 ; 7.9 ; 11.7$ & -1 & -0.4 & A \\
\hline Diclofenac & [15307-86-5] & 296.2 & 4.51 & 4.1 & -1 & 3.0 & A \\
\hline Fenofibrate & [49562-28-9] & 360.8 & 5.19 & NA & 0 & 5.2 & $\mathrm{~N}$ \\
\hline Gabapentin & [60142-96-3] & 171.2 & -1.1 & $3.7 ; 10.0$ & $\mathrm{Z}$ & -1.1 & $\mathrm{Z}$ \\
\hline Gemfibrozil & [25812-30-0] & 250.3 & 4.77 & 4.7 & -1 & 3.4 & A \\
\hline Ibuprofen & [15687-27-1] & 206.3 & 3.97 & 4.9 & -1 & 2.6 & A \\
\hline Iohexol & [66108-95-0] & 821.1 & -3.05 & NA & 0 & -3.1 & $\mathrm{~N}$ \\
\hline Iomeprol & [78649-41-9] & 777.1 & -2.79 & $11.7 ; 12.6 ; 13.6$ & 0 & -2.8 & $\mathrm{~N}$ \\
\hline Iopamidol & [60166-93-0] & 777.1 & -2.42 & $11.1 ; 12.9$ & 0 & -2.4 & $\mathrm{~N}$ \\
\hline Iopromide & [73334-07-3] & 791.1 & -2.05 & 11.4 & 0 & -2.1 & $\mathrm{~N}$ \\
\hline Iothalamic acid & [2276-90-6] & 613.9 & 0.5 & $2.1 ; 11.2 ; 12.6$ & -1 & -1.2 & A \\
\hline Ketoprofen & [22071-15-4] & 254.3 & 3.12 & 4.5 & -1 & 1.7 & A \\
\hline Mefenamic acid & [61-68-7] & 241.3 & 5.12 & 4.2 & -1 & 3.7 & A \\
\hline Metoprolol & [37350-58-6] & 267.4 & 1.88 & 9.7 & 1 & 0.4 & B \\
\hline Metronidazole & [443-48-1] & 171.2 & -0.02 & 2.5 & 0 & 0.0 & $\mathrm{~N}$ \\
\hline Nadolol & [42200-33-9] & 309.4 & 0.81 & 9.7 & 1 & -0.6 & B \\
\hline Naproxen & [22204-53-1] & 230.3 & 3.18 & 4.2 & -1 & 1.7 & A \\
\hline Norfloxacin & [70458-96-7] & 319.3 & -1.03 & $6.4 ; 8.7$ & $\mathrm{Z} ; 0 ;-1$ & -1.0 & $\mathrm{Z}$ \\
\hline Ofloxacin & [82419-36-1] & 361.4 & -0.39 & $5.7 ; 7.1$ & $\mathrm{Z} ; 0 ;-1$ & -0.4 & $\mathrm{Z}$ \\
\hline Paracetamol & [103-90-2] & 151.2 & 0.46 & 9.4 & 0 & 0.5 & $\mathrm{~N}$ \\
\hline Pravastatin & [81093-37-0] & 424.5 & 3.1 & 4.5 & -1 & 1.7 & A \\
\hline Primidone & [125-33-7] & 218.3 & 0.91 & NA & 0 & 0.9 & $\mathrm{~N}$ \\
\hline Propranolol & [525-66-6] & 259.3 & 3.48 & 9.4 & 1 & 2.1 & B \\
\hline Simvastatin & [79902-63-9] & 418.6 & 4.68 & 13.5 & 0 & 4.7 & $\mathrm{~N}$ \\
\hline Sotalol & [3930-20-9] & 272.4 & 0.24 & $8.2 ; 9.1$ & 1 & -0.9 & B \\
\hline Sulfadimethoxine & [122-11-2] & 310.3 & 1.63 & $2.0 ; 6.7$ & -1 & 1.0 & A \\
\hline Sulfamethoxazole & [723-46-6] & 253.3 & 0.89 & $1.8 ; 5.8$ & -1 & -0.2 & A \\
\hline Trimethoprim & {$[738-70-5]$} & 290.3 & 0.91 & $1.3 ; 7.2$ & $1 ; 0$ & 0.4 & $\mathrm{~B}$ \\
\hline \multicolumn{8}{|c|}{ Endocrine disrupting compounds } \\
\hline $17 \alpha$-Ethinylestradiol & {$[57-63-6]$} & 296.4 & 3.67 & 10.4 & 0 & 3.7 & $\mathrm{~N}$ \\
\hline Bisphenol A & {$[80-05-7]$} & 228.3 & 3.32 & 10.1 & 0 & 3.3 & $\mathrm{~N}$ \\
\hline Estriol & {$[50-27-1]$} & 288.4 & 2.45 & 10.4 & 0 & 2.5 & $\mathrm{~N}$ \\
\hline Estrone & [53-16-7] & 270.4 & 3.13 & 10.3 & 0 & 3.1 & $\mathrm{~N}$ \\
\hline Nonylphenol & {$[84852-15-3]$} & 220.4 & 5.92 & 11.1 & 0 & 5.9 & $\mathrm{~N}$ \\
\hline$\beta$-Estradiol & [50-28-2] & 272.4 & 4.01 & 10.5 & 0 & 4.0 & $\mathrm{~N}$ \\
\hline \multicolumn{8}{|c|}{ Pesticides and other common chemicals } \\
\hline Atrazine & [1912-24-9] & 215.7 & 2.61 & 1.7 & 0 & 2.6 & $\mathrm{~N}$ \\
\hline Benzotriazole & {$[95-14-7]$} & 119.1 & 1.44 & 8.4 & 0 & 1.4 & $\mathrm{~N}$ \\
\hline Carbendazim & {$[10605-21-7]$} & 191.2 & 1.52 & 4.2 & 0 & 1.5 & $\mathrm{~N}$ \\
\hline Chloridazon & {$[1698-60-8]$} & 221.6 & 1.14 & 3.4 & 0 & 1.1 & $\mathrm{~N}$ \\
\hline Diazinon & [333-41-5] & 304.4 & 3.81 & 2.4 & 0 & 3.8 & $\mathrm{~N}$ \\
\hline Diuron & {$[330-54-1]$} & 233.1 & 2.68 & 13.6 & 0 & 2.7 & $\mathrm{~N}$ \\
\hline IPBC & [55406-53-6] & 281.1 & 2.54 & NA & 0 & 2.5 & $\mathrm{~N}$ \\
\hline Irgarol & [28159-98-0] & 253.4 & 4.07 & NA & 0 & 4.1 & $\mathrm{~N}$ \\
\hline Isoproturon & [34123-59-6] & 206.3 & 2.87 & NA & 0 & 2.9 & $\mathrm{~N}$ \\
\hline Mecoprop & [93-65-2] & 214.7 & 3.13 & 3.1 & -1 & 1.5 & A \\
\hline Methylbenzotriazole & [29385-43-1] & 133.2 & 1.71 & 8.8 & 0 & 1.7 & $\mathrm{~N}$ \\
\hline Propiconazole & [60207-90-1] & 342.2 & 3.72 & 1.1 & 0 & 3.7 & $\mathrm{~N}$ \\
\hline Tebufenozide & [112410-23-8] & 352.5 & 4.25 & NA & 0 & 4.3 & $\mathrm{~N}$ \\
\hline Terbutryn & [886-50-0] & 241.4 & 3.74 & 4.3 & 0 & 3.7 & $\mathrm{~N}$ \\
\hline Triclosan & [3380-34-5] & 289.5 & 4.76 & 7.8 & $0 ;-1$ & 4.8 & $\mathrm{~N}$ \\
\hline
\end{tabular}


Table S2. Sample preparation for estrogens analyses and enrichment for the bioassays (YES, algae assay).

\begin{tabular}{|c|c|c|}
\hline & Solid phase extraction for estrogens & Solid phase extraction for bioassays \\
\hline \multicolumn{3}{|l|}{ General Information } \\
\hline Sample type & \multicolumn{2}{|c|}{ Water samples } \\
\hline Sample volumes & $\begin{array}{l}250 \mathrm{ml} \text { wastewater influent } \\
500 \mathrm{ml} \text { wastewater effluent }\end{array}$ & $\begin{array}{l}200 \mathrm{ml} \text { wastewater influent } \\
500 \mathrm{ml} \text { wastewater effluent }\end{array}$ \\
\hline Blank & \multicolumn{2}{|c|}{$500 \mathrm{ml}$ ultrapure water } \\
\hline \multicolumn{3}{|l|}{ Sample preparation } \\
\hline Filtration & \multicolumn{2}{|c|}{ Yes, with glass fibre filter type APFD $09050(1 \mu \mathrm{m})$ (Millipore) } \\
\hline Acidification $-m$ & \multicolumn{2}{|c|}{ Yes, with $\mathrm{HCl}$ to $\mathrm{pH} 3$} \\
\hline $\begin{array}{l}\text { Addition of isotope-labelled } \\
\text { internal mixed standard } \\
\text { solution (IS) }\end{array}$ & $\begin{array}{l}30 \mathrm{ng} \text { EE2-D4, E2-13C2, E1-D4, } \\
\text { BPA-D16 and NP-13C6 to each } \\
\text { sample }\end{array}$ & No \\
\hline Sample enrichment & \multicolumn{2}{|c|}{ Solid phase extraction (SPE) } \\
\hline SPE cartridges & \multicolumn{2}{|c|}{$\begin{array}{l}\text { LiChrolut EN RP-18 (bottom: } 100 \mathrm{mg} \text { LiChrolut EN, top: } 200 \mathrm{mg} \text { LiChrolut } \\
\text { RP 18) }\end{array}$} \\
\hline Conditioning & $\begin{array}{l}6 \mathrm{ml} \text { Hexane } \\
2 \mathrm{ml} \text { Acetone } \\
6 \mathrm{ml} \text { Methanol } \\
10 \mathrm{ml} \text { Water }(\mathrm{pH} \mathrm{3.0)}\end{array}$ & $\begin{array}{l}2 \mathrm{ml} \text { Hexane } \\
2 \mathrm{ml} \text { Acetone } \\
6 \mathrm{ml} \text { Methanol } \\
6 \mathrm{ml} \text { Water }(\mathrm{pH} \mathrm{3.0)}\end{array}$ \\
\hline Washing & $\begin{array}{l}8 \mathrm{ml} \text { Methanol/Water }(70: 30, \mathrm{v} / \mathrm{v}) \\
6 \mathrm{ml} \text { Acetonitrile/Water }(30: 70, \mathrm{v} / \mathrm{v})\end{array}$ & $\begin{array}{l}\text { No, only filling of the cartridge with } \\
\text { water (pH 3.0) }\end{array}$ \\
\hline Elution & $4 \mathrm{ml}$ Acetone & $\begin{array}{l}4 \mathrm{ml} \text { Acetone } \\
1 \mathrm{ml} \text { Methanol }\end{array}$ \\
\hline Evaporation & With $\mathrm{N}_{2}$ to ca. $100 \mu \mathrm{l}$ & $\begin{array}{l}\text { With } \mathrm{N}_{2} \text { to ca. } 500 \mu \mathrm{l} \text {, then completing } \\
\text { to } 1000 \mu \mathrm{l} \text { with ethanol }\end{array}$ \\
\hline Enrichment factor & $\begin{array}{l}1250 \times \text { wastewater influent } \\
2500 \times \text { wastewater effluent }\end{array}$ & $\begin{array}{l}200 \times \text { wastewater influent } \\
500 \times \text { wastewater effluent }\end{array}$ \\
\hline \multicolumn{3}{|c|}{ Purification and storage of sample extract } \\
\hline Sorbent & $\begin{array}{l}\text { Mini silica gel columns }(1.00 \pm 0.01 \\
\mathrm{g})\end{array}$ & No \\
\hline Application of sample & $\begin{array}{l}100 \mu \mathrm{l} \text { sample }+2 \times 0.2 \mathrm{ml} \\
\text { Hexane/Acetone }(60: 40, \mathrm{v} / \mathrm{v})\end{array}$ & \\
\hline Elution & $7.1 \mathrm{ml}$ Hexane/Acetone $(60: 40, \mathrm{v} / \mathrm{v})$ & \\
\hline Evaporation & $\begin{array}{l}\text { To dryness, fill-up with } 200 \mu \mathrm{l} \\
\text { Ethanol }\end{array}$ & \\
\hline Storage & \multicolumn{2}{|c|}{ In the dark, at $-20^{\circ} \mathrm{C}$} \\
\hline
\end{tabular}


Table S3. Specification for LC-MS/MS analytics of estrogenic active substances.

\begin{tabular}{|c|c|}
\hline LC-MS/MS analysis & \\
\hline LC-MS/MS instrument & API 4000 LC-MS/MS (Applied Biosystems, Warrington, UK) \\
\hline HPLC separation & $\begin{array}{l}\text { Gradient elution } \\
\text { Eluent } \mathrm{A}=\text { water/acetonitrile }(90: 10, \mathrm{v} / \mathrm{v}) \\
\text { Eluent } \mathrm{B}=\text { acetonitrile/water }(90: 10, \mathrm{v} / \mathrm{v})\end{array}$ \\
\hline HPLC column & MS C18 HPLC column (2.1 mm x $100 \mathrm{~mm}$, particle size $3.5 \mu \mathrm{m})$ \\
\hline Ionisation & Negative electrospray ionisation (ESI') \\
\hline Calibration & $\begin{array}{l}0-200 \mathrm{ng} / \mathrm{ml} \mathrm{E} 1 \text {, E2 and EE2 mixed standards } \\
0-2500 \mathrm{ng} / \mathrm{ml} \mathrm{NP}+\mathrm{BPA} \text { standards }\end{array}$ \\
\hline Replicates & 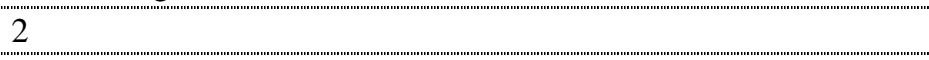 \\
\hline Limit of quantification & E1 0.6 ng/l; E2 1.1 ng/l; EE2 3.0 ng/l; BPA 4.9 ng/l; NP 22.9 ng/l \\
\hline
\end{tabular}

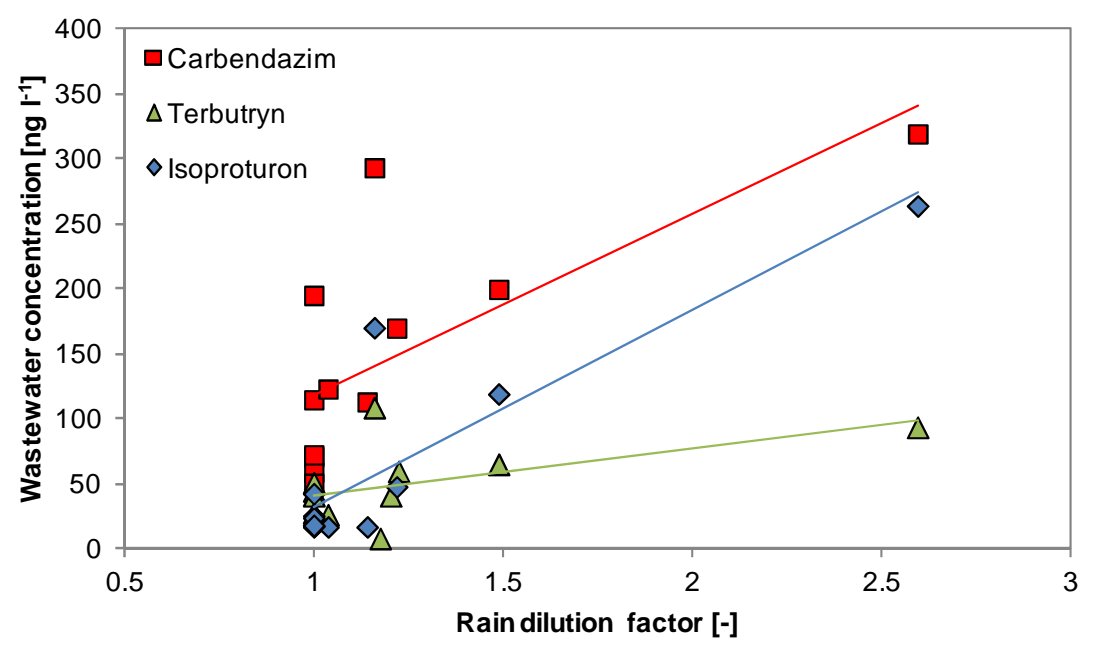

Figure S1. Concentration of selected pesticides in raw wastewater as a function of wastewater dilution by runoff water. Correlations with the dilution factor (wet weather flow/dry weather flow): Isoproturon $(\mathrm{r}=0.875, \mathrm{p}<$ $0.001)$, carbendazim $(r=0.712, p<0.01)$, terbutryn $(r=0.612, p<0.05)$. 
a

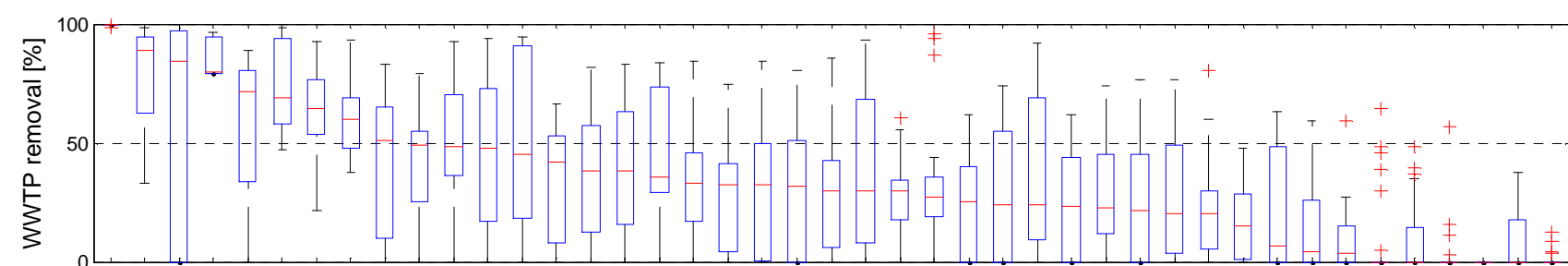

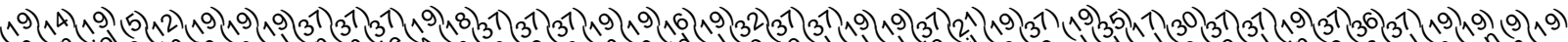

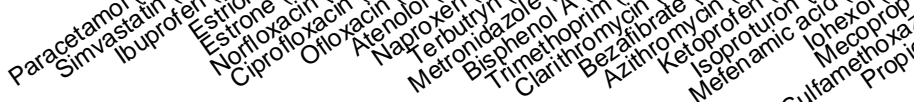

gut
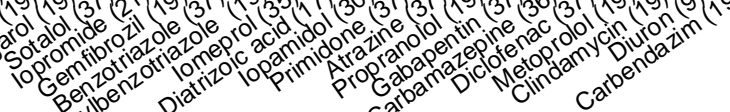$$
\text { Nent }
$$$$
\text { b }
$$
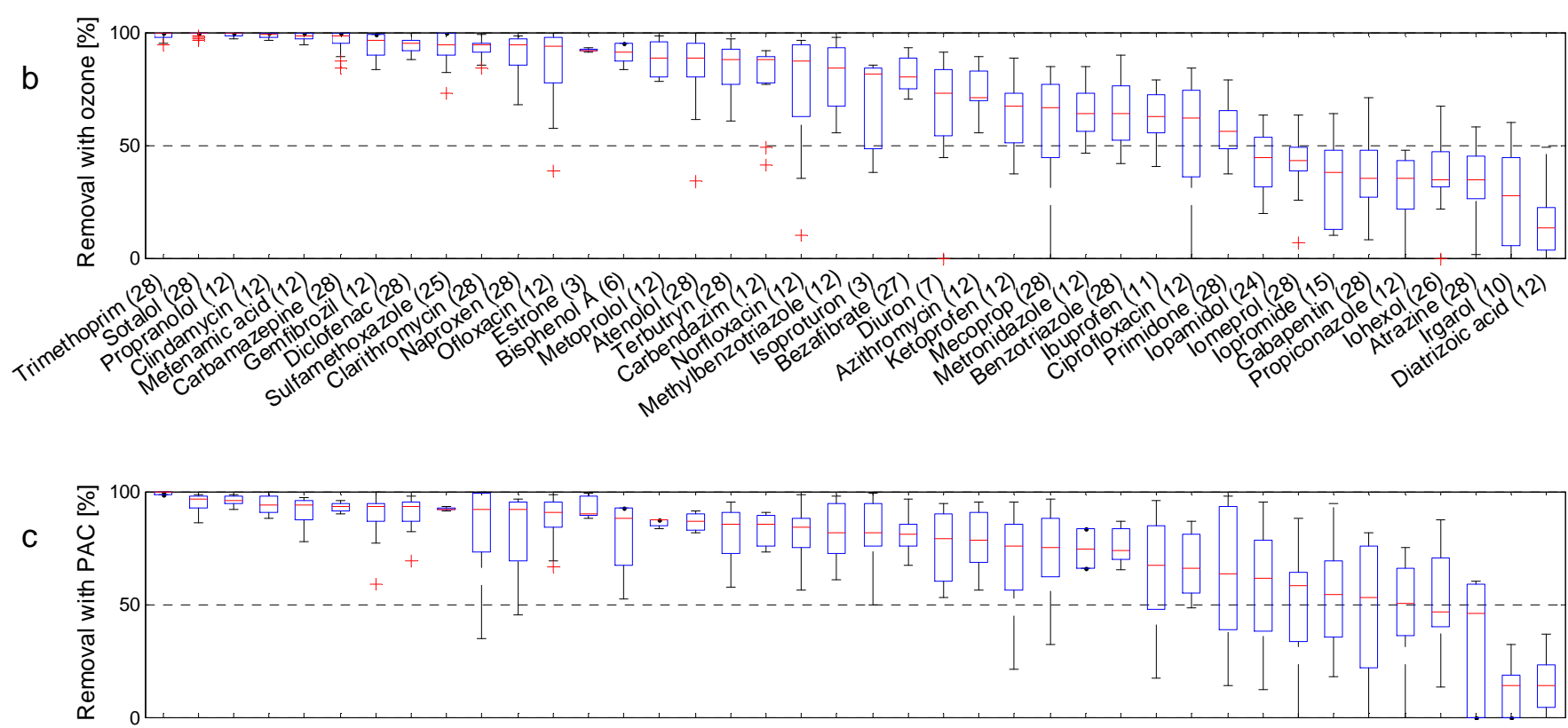

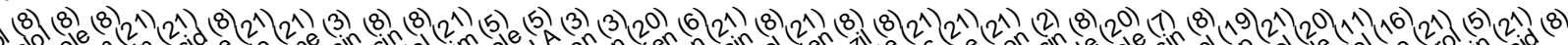

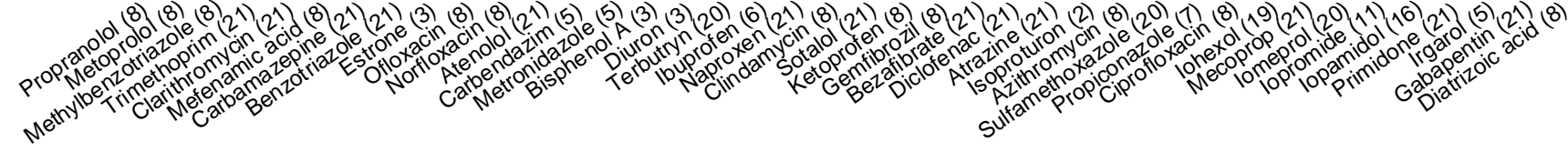

Figure S2. Removal efficiency of 40 to 43 micropollutants during (a) the conventional biological wastewater treatment with either activated sludge without nitrification or moving bed bioreactor with partial to complete nitrification (average removal of 35\%), (b) the ozonation (ozone dose between 2.3 to $9.1 \mathrm{mg} \mathrm{O}_{3} \mathrm{l}^{-1}$, median 5.9 $\mathrm{mg} \mathrm{O}_{3} \mathrm{I}^{-1}$ or $0.83 \mathrm{~g} \mathrm{O}_{3} \mathrm{~g}^{-1}$ DOC, average removal of $71 \%$ ) and (c) the PAC-UF treatment (PAC dose between 10

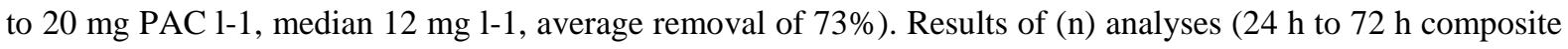
samples) conducted between June 2009 and October 2010. Representation of the median removal, the quartiles $25-75 \%$, the minimum and maximum values and the outliers. 
Effect of the nitrification level on the removal of 18 micropollutants
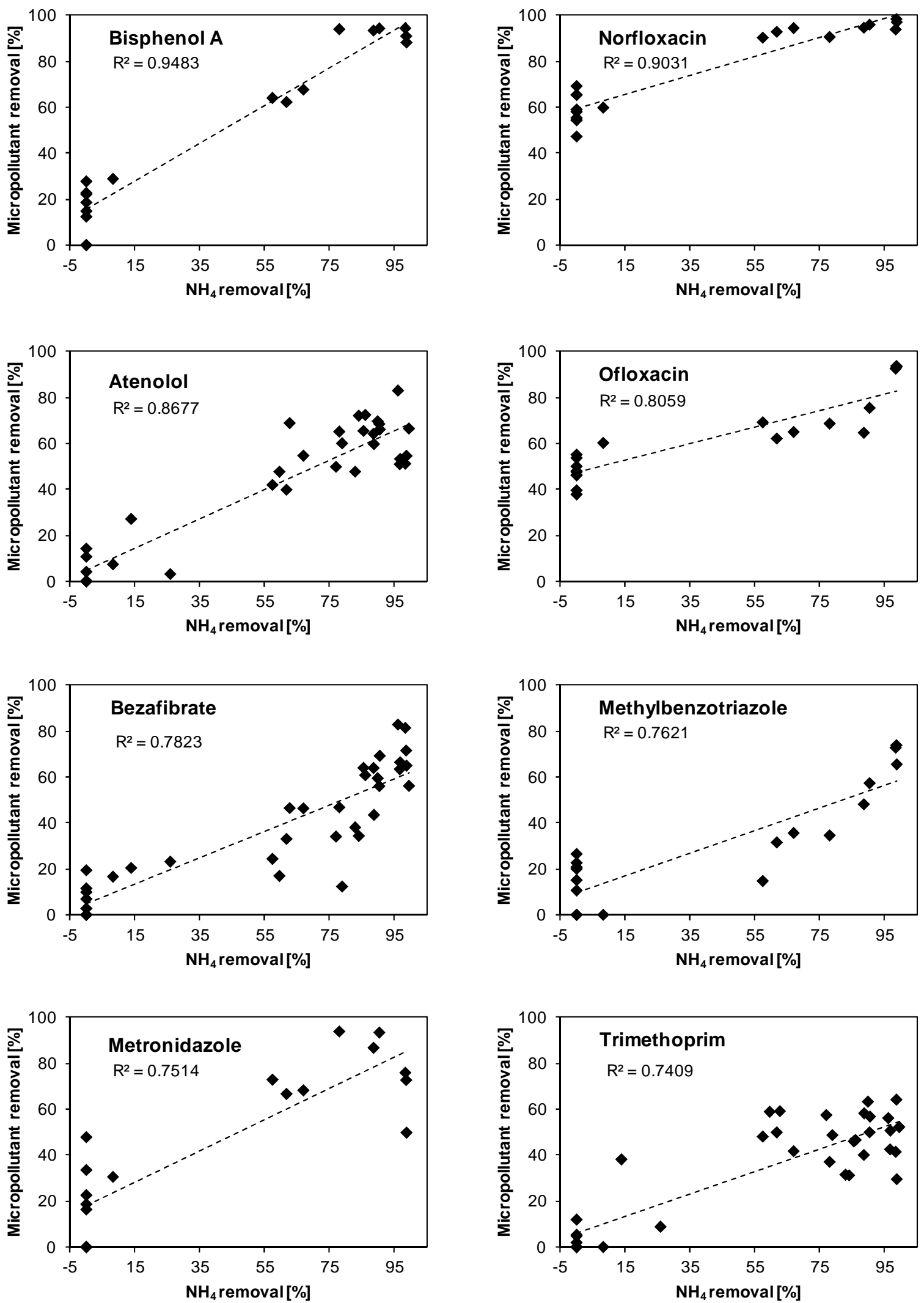

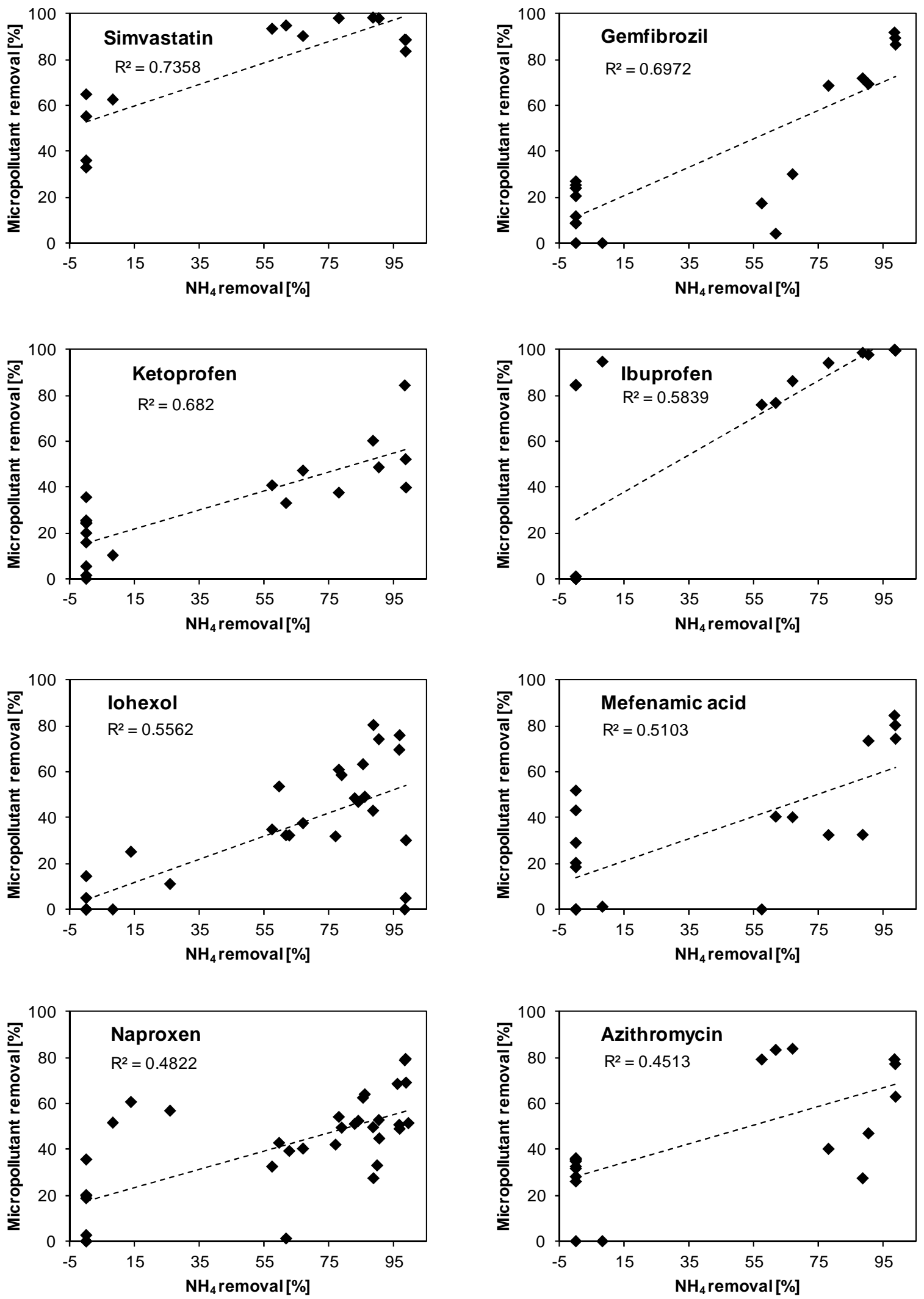

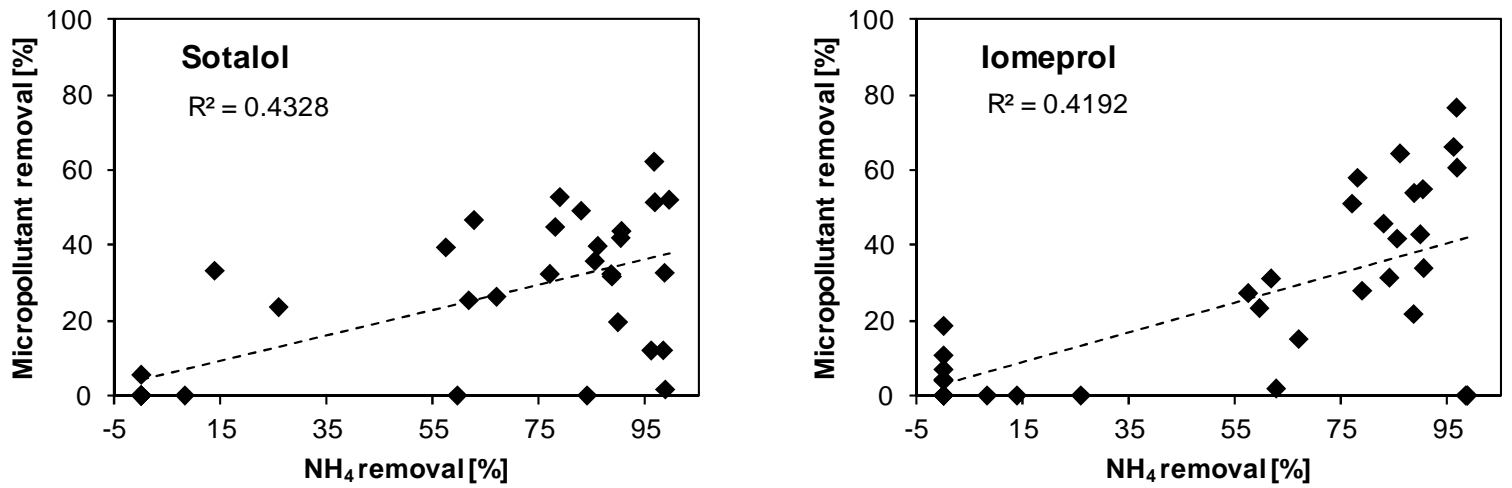

Figure S3. Removal of 18 micropollutants in the biological treatment as a function of the level of nitrification (ammonium removal). Results of 19 to 36 campaigns on 24 to 72-h composite samples at the entrance of the WWTP and at the outlet of the biological treatment. Diverse levels of nitrification were obtained by varying the hydraulic residence time or the aeration either in an activated sludge tank with a sludge age of $2 \mathrm{~d}(0$ to $26 \%$ of nitrification, 9 to $21 \mathrm{mg} \mathrm{N}-\mathrm{NH}_{4} \mathrm{l}^{-1}$ in the effluent) or in a moving bed bioreactor (57 to $99 \%$ of nitrification, 0.1 to $10 \mathrm{mg} \mathrm{N}-\mathrm{NH}_{4} \mathrm{l}^{-1}$ in the effluent). Of the 42 compounds regularly detected, 24 had a significant $(\mathrm{p}<0.05)$ positive correlation of their removal with the level of nitrification, among which 11 had a strong correlation $(r>$ 0.8 ) and seven a medium correlation $(0.6<r<0.8)$ (Table S4). Compounds with $r>0.6$ are presented here. There were 18 compounds that were not significantly influenced by the nitrifying efficiency of the biological treatment, including the very common pollutants carbamazepine, diclofenac, gabapentin, sulfamethoxazole, benzotriazole and mecoprop.

Table S4. Correlation coefficients between the removal of 42 micropollutants and the level of nitrification (\% of ammonium removal) in the biological treatment. Pearson correlation on 19 to 36 analyses. Correlations were considered significant for $\mathrm{p}$ values $<0.05$.

\begin{tabular}{|c|c|c|c|}
\hline Substance & Correlation & Substance & Correlation \\
\hline Bisphenol A & $0.97^{* * *}$ & Irgarol & $0.48^{*}$ \\
\hline Norfloxacin & $0.95^{* * *}$ & Clarithromycin & $0.43^{* *}$ \\
\hline Atenolol & $0.93^{* * *}$ & Terbutryn & $0.36^{*}$ \\
\hline Ofloxacin & $0.90^{* * *}$ & Paracetamol & $0.29^{\mathrm{ns}}$ \\
\hline Bezafibrate & $0.88^{* * *}$ & Isoproturon & $0.27^{\mathrm{ns}}$ \\
\hline Methylbenzotriazole & $0.87^{* * *}$ & Benzotriazole & $0.26^{\mathrm{ns}}$ \\
\hline Metronidazole & $0.87^{* * *}$ & Carbendazim & $0.24^{\mathrm{ns}}$ \\
\hline Trimethoprim & $0.86^{* * *}$ & Estrone & $0.20^{\mathrm{ns}}$ \\
\hline Simvastatin & $0.86^{* * *}$ & Propiconazol & $0.20^{\mathrm{ns}}$ \\
\hline Gemfibrozil & $0.83^{* * *}$ & Mecoprop & $0.19^{\mathrm{ns}}$ \\
\hline Ketoprofen & $0.83^{* * *}$ & Iopamidol & $0.16^{\mathrm{ns}}$ \\
\hline Ibuprofen & $0.76^{* * *}$ & Diclofenac & $0.14^{\mathrm{ns}}$ \\
\hline Iohexol & $0.75^{* * *}$ & Carbamazepine & $0.12^{\mathrm{ns}}$ \\
\hline Mefenamic acid & $0.71^{* * *}$ & Ciprofloxacin & $0.12^{\mathrm{ns}}$ \\
\hline Naproxen & $0.69^{* * *}$ & Gabapentin & $0.05^{\mathrm{ns}}$ \\
\hline Azithromycin & $0.67^{* *}$ & Clindamycin & $0.00^{\mathrm{ns}}$ \\
\hline Sotalol & $0.66^{* * *}$ & Sulfamethoxazole & $-0.08^{\mathrm{ns}}$ \\
\hline Iomeprol & $0.65^{* * *}$ & Diatrizoic + iothalamic acid & $-0.13^{\mathrm{ns}}$ \\
\hline Propranolol & $0.57^{*}$ & Metoprolol & $-0.22^{\mathrm{ns}}$ \\
\hline Primidone & $0.53^{* * *}$ & Atrazine & $-0.41^{*}$ \\
\hline Iopromide & $0.50^{*}$ & Diuron & $-0.42^{\mathrm{ns}}$ \\
\hline
\end{tabular}



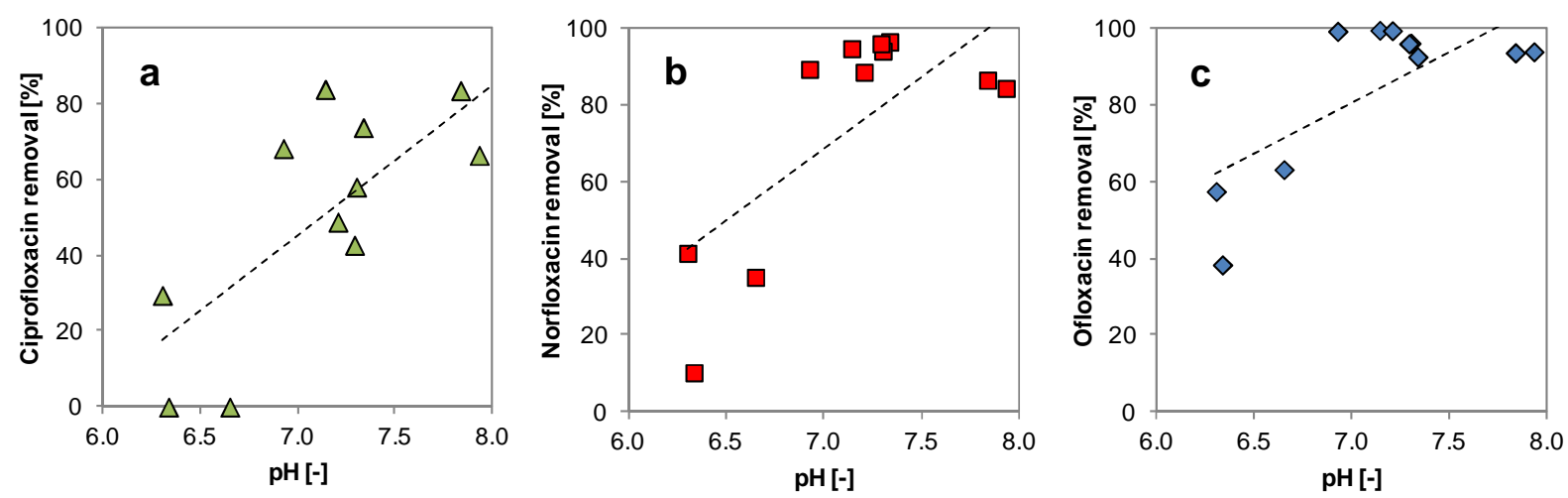

Figure S4. Removal of fluoroquinolone antibiotics by ozonation (in the pilot plant) as a function of the feed water pH. (a) Ciprofloxacine. (b) Norfloxacin. (c) Ofloxacin. Ozone doses varied between 3 and $7 \mathrm{mg} \mathrm{O}_{3} \mathrm{l}^{-1}$ to maintain the same residual dissolved ozone concentration in the third chamber of the reactor. No clear link between the ozone dose and the removal of these three compounds was evident, suggesting that the $\mathrm{pH}$ was the most influential factor. Correlations of the removal rate with the $\mathrm{pH}$ : Ciprofloxacin $(\mathrm{r}=0.76 \mathrm{p}=0.004)$, norfloxacin $(r=0.73, p=0.007)$, ofloxacin $(r=0.74, p=0.006)$.
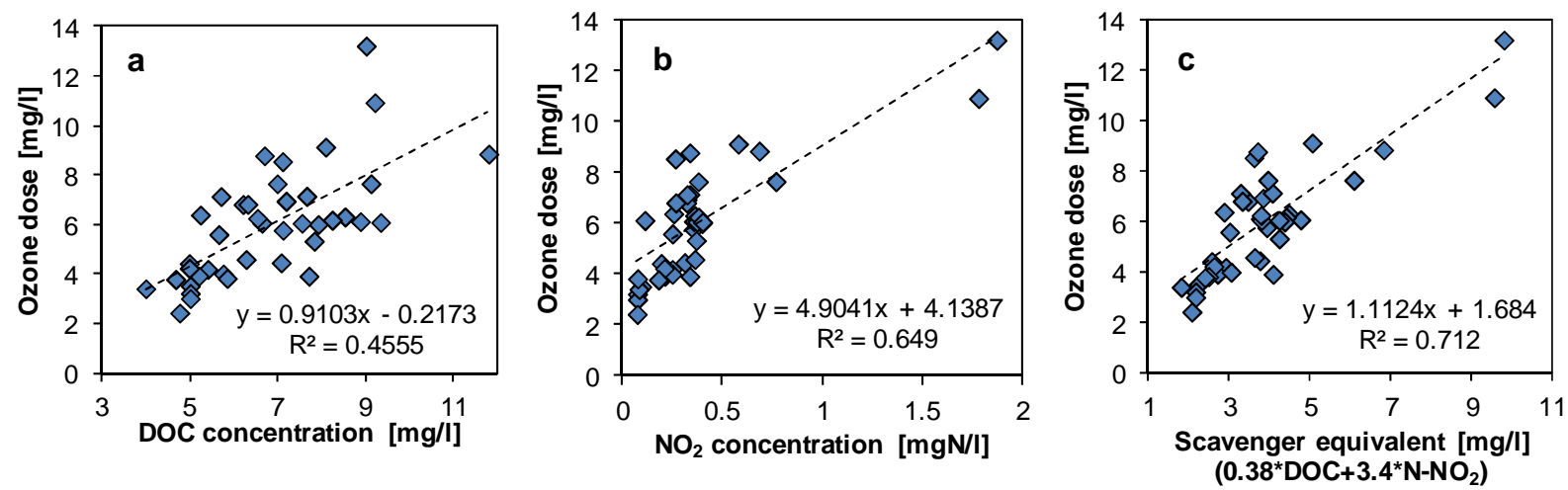

Figure S5. Influence of the daily average ozone dosage in the reactor as a function of daily average concentrations of (a) dissolved organic carbon (DOC), (b) nitrite, and (c) scavenger equivalent, calculated by the optimal (maximizing $\mathrm{R}^{2}$ ) weighted sum of DOC and $\mathrm{NO}_{2}$ concentrations (in $\mathrm{mg} \mathrm{l}^{-1}$ ): $0.38 \mathrm{DOC}+3.4 \mathrm{~N}-\mathrm{NO}_{2}$. The ozone dose was regulated to maintain the same residual dissolved ozone concentration $\left(\sim 0.1 \mathrm{mg} \mathrm{l}^{-1}\right)$ in the third chamber of the reactor and thus varied depending of the oxidative demand of the water, mainly due to DOC and nitrite concentration. 
Influence of the ozone dose on the removal of 15 micropollutants by ozonation

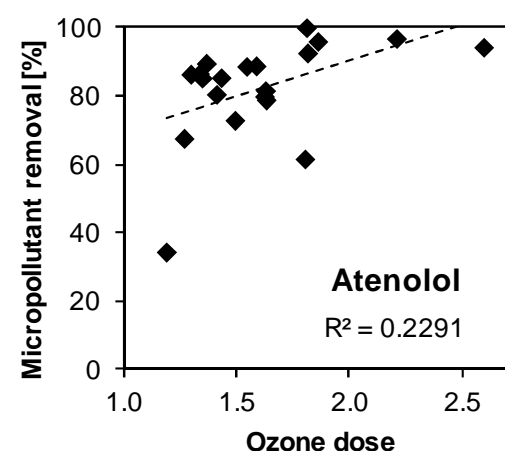

[g O $\mathrm{O}_{3} / \mathrm{g}$ scavenger equivalent]

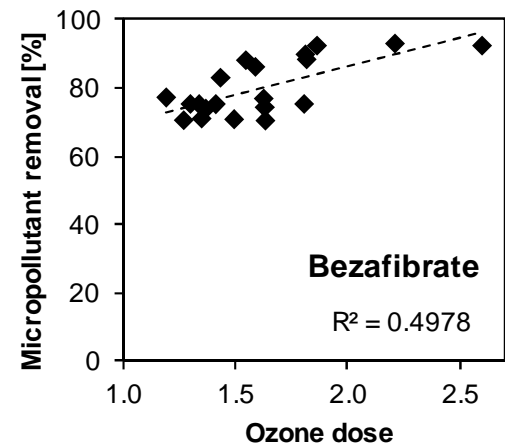

[g $\mathrm{O}_{3} / \mathrm{g}$ scavenger equivalent]

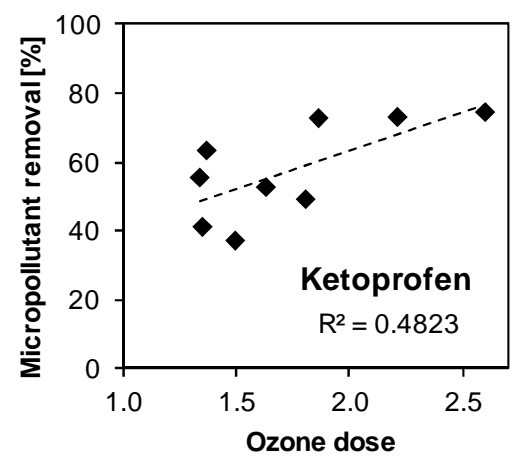

[ $\mathrm{g} \mathrm{O}_{3} / \mathrm{g}$ scavenger equivalent]

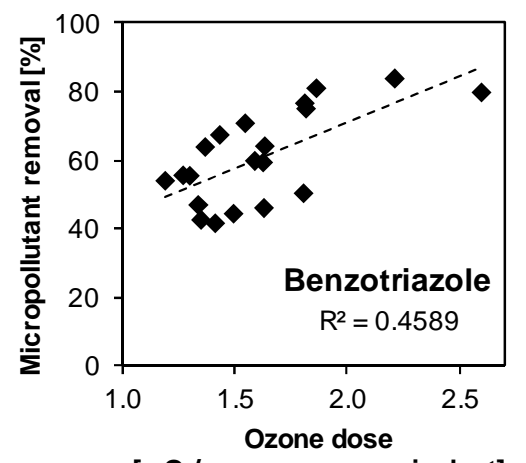

[ $\mathrm{g} \mathrm{O}_{3} / \mathrm{g}$ scavenger equivalent]

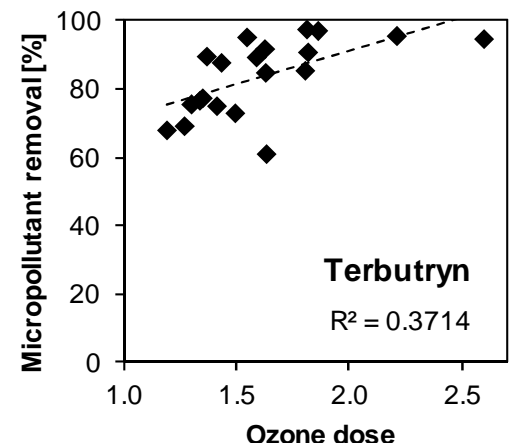

[g $\mathrm{O}_{3} / \mathrm{g}$ scavenger equivalent]

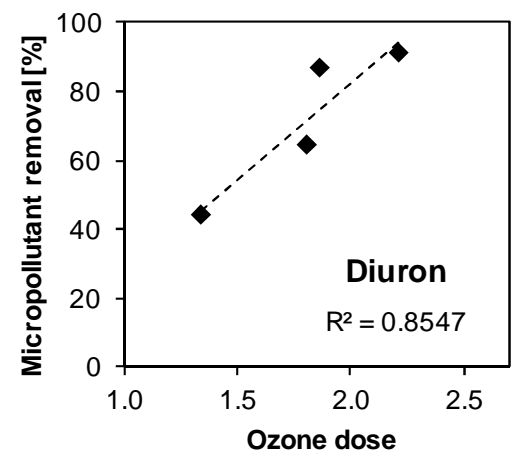

[ $\mathrm{g} \mathrm{O}_{3} / \mathrm{g}$ scavenger equivalent]

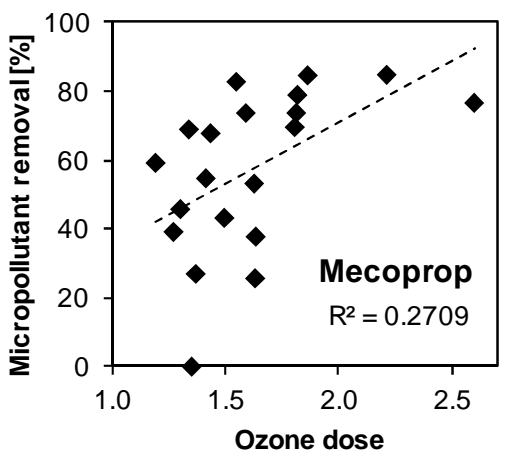

[g $\mathrm{O}_{3} / \mathrm{g}$ scavenger equivalent]

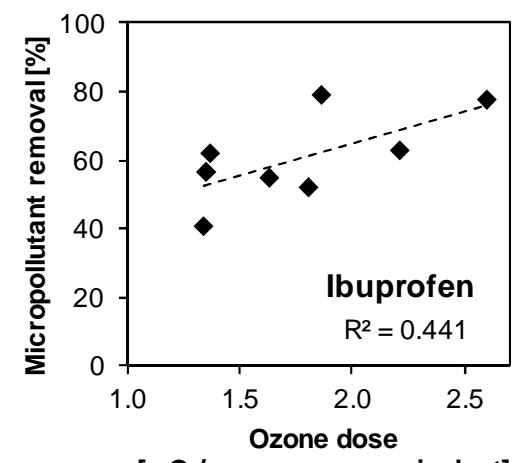

[g $\mathrm{g}_{3} / \mathrm{g}$ scavenger equivalent]

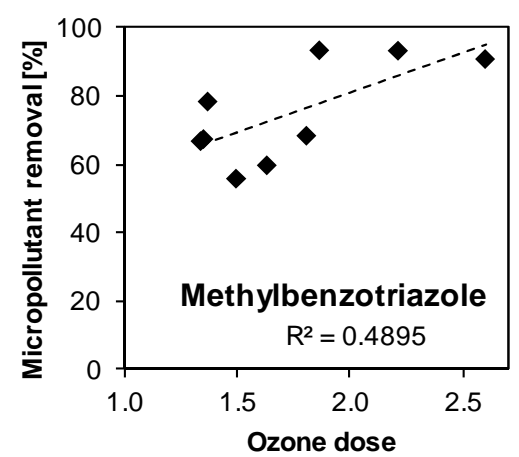

[g $\mathrm{O}_{3} / \mathrm{g}$ scavenger equivalent]

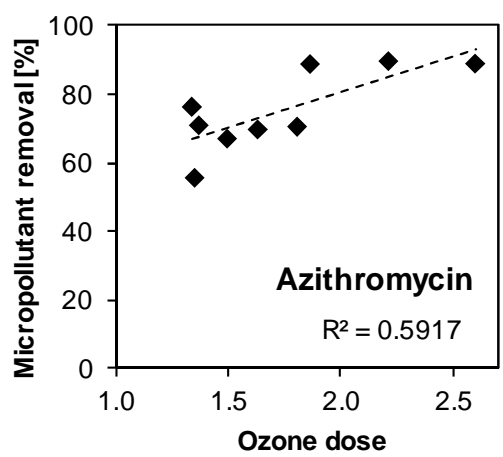

[ $\mathrm{g} \mathrm{O}_{3} / \mathrm{g}$ scavenger equivalent]

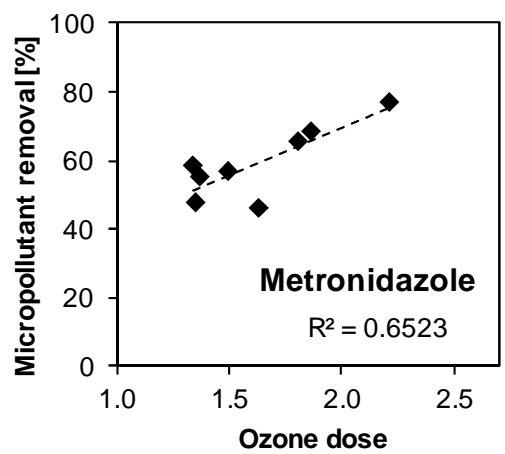

[ $\mathrm{g} \mathrm{O}_{3} / \mathrm{g}$ scavenger equivalent]

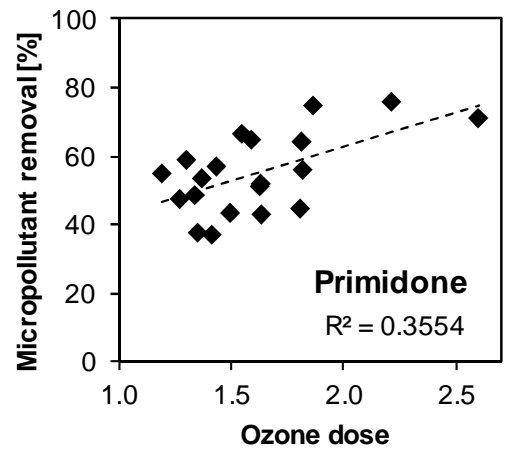

[ $\mathrm{g} \mathrm{O}_{3} / \mathrm{g}$ scavenger equivalent] 

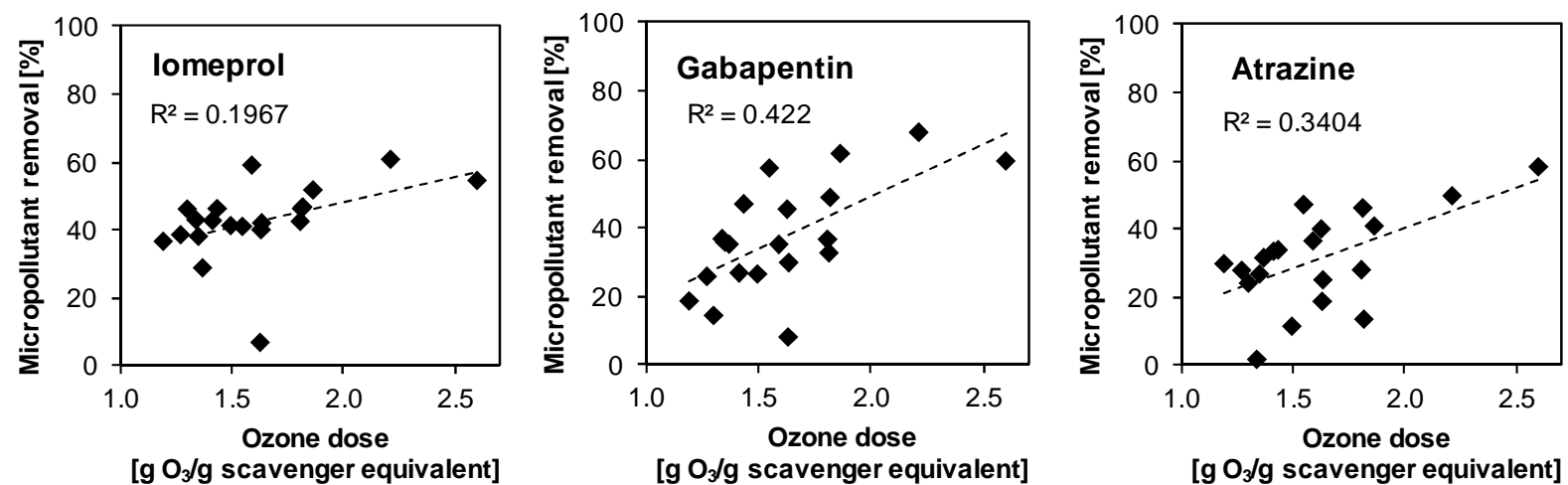

Figure S6. Influence of the daily average ozone dose on the removal of 15 micropollutants by ozonation. Results of 20 campaigns conducted on the effluent of a moving bed bioreactor with partial nitrification. The ozone dose is normalized by the scavenger equivalent concentration, calculated by the weighted sum of DOC and $\mathrm{NO}_{2}$ concentrations (in $\mathrm{mg} \mathrm{l}^{-1}$ ): $0.38 \mathrm{DOC}+3.4 \mathrm{~N}^{-\mathrm{NO}_{2}}$.

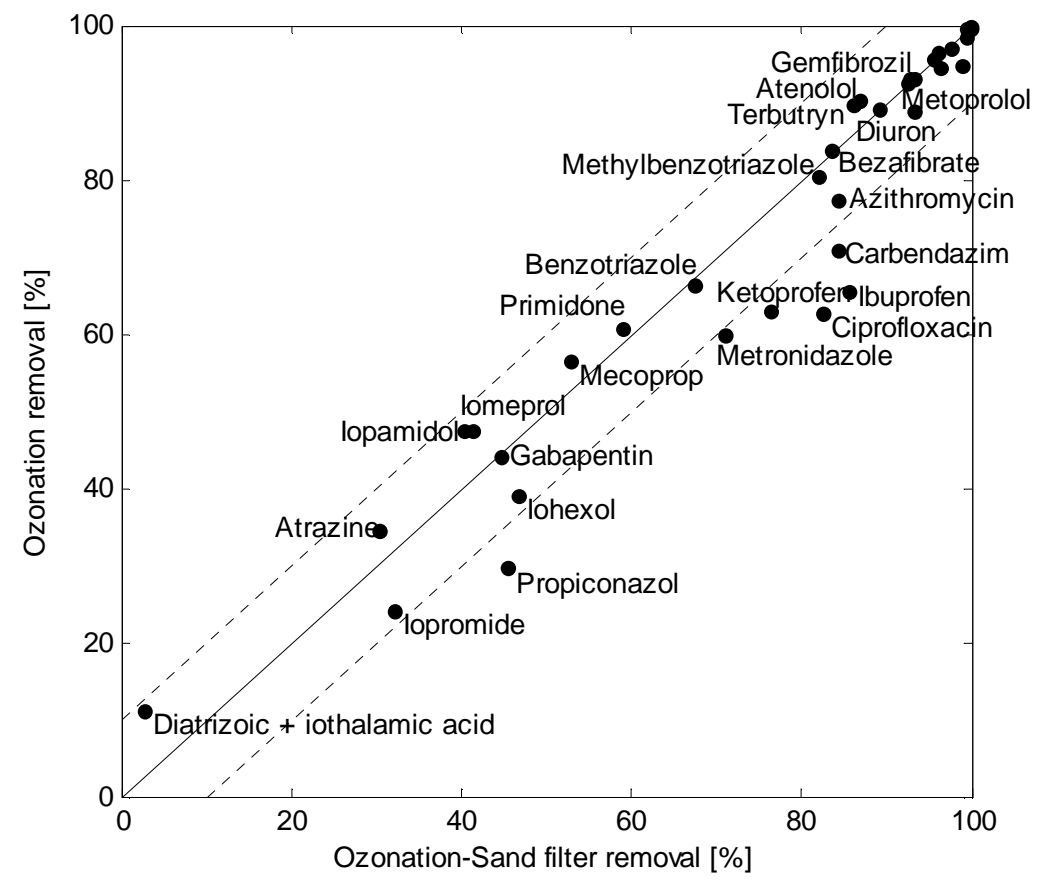

Figure S7. Comparison of the removal of 36 micropollutants with ozone alone or with ozone followed by a sand filter (SF). Black line: similar removal by ozone alone or by ozone + SF. Dashed line: $10 \%$ difference between the removal by ozone alone or by ozone + SF. Average of 8 sampling campaigns (24 to 72-h composite samples). Average removal of the 36 compounds was $73.2 \%$ for ozone and $75.8 \%$ for ozone + SF. 
- Bromide $\square$ Bromate - - - Swiss drinking water standard for bromate

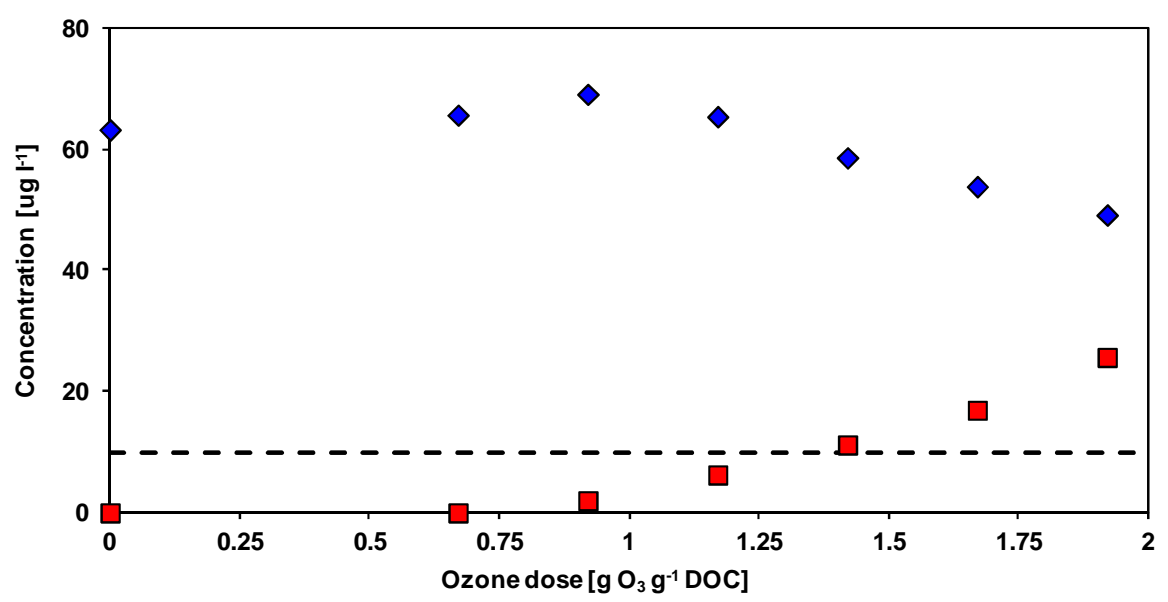

Figure S8. Influence of the ozone dose on bromate formation. Laboratory-scale oxidation experiments were conducted on 24-h composite wastewater samples collected at the Lausanne WWTP after biological treatment with full nitrification ( $5 \mathrm{mg}$ DOC $\mathrm{l}^{-1}, 0.6 \mathrm{mg} \mathrm{N}-\mathrm{NO}_{2} \mathrm{l}^{-1}$ ). Different amounts of a stock solution of dissolved ozone (in water) were added to the samples to reach the desired ozone concentration (from 0 to $9.6 \mathrm{mg} \mathrm{O}_{3} \mathrm{l}^{-1}$ ). At low doses ( $<1 \mathrm{~g} \mathrm{O}_{3} \mathrm{~g}^{-1}$ DOC), only negligible oxidation of bromide to bromate occurred due to fast ozone consumption by nitrite and reactive DOC. Above $0.9 \mathrm{~g} \mathrm{O}_{3} \mathrm{~g}^{-1} \mathrm{DOC}$, a linear relation between the ozone dose and bromate formation was observed. At $1.4 \mathrm{~g} \mathrm{O}_{3} \mathrm{~g}^{-1}$ DOC $\left(7 \mathrm{mg} \mathrm{O}_{3} \mathrm{l}^{-1}\right)$, the Swiss drinking water standard for bromate $\left(10 \mu \mathrm{g} \mathrm{l}^{-1}\right)$ was satisfied. 

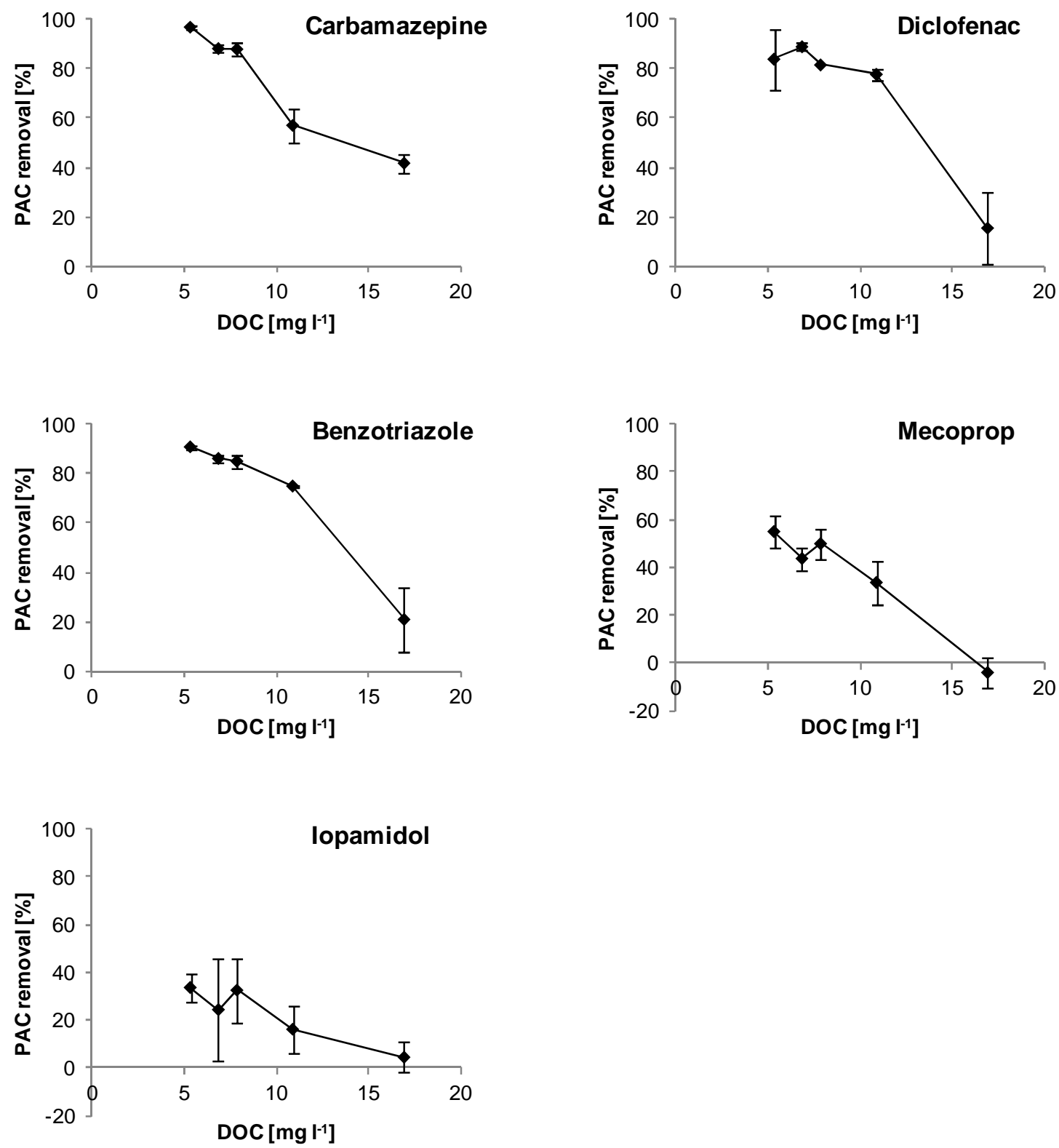

Figure S9. Influence of dissolved organic carbon (DOC) wastewater concentration on powdered activated carbon (PAC) removal efficiency of five micropollutants in wastewater. Average (diamonds) and standard deviation (vertical bars) of triplicates. Laboratory-scale batch adsorption experiments were conducted on 24-h composite wastewater samples collected during the same period at the Lausanne WWTP after either simple coagulation-precipitation treatment (DOC of $17 \mathrm{mg} \mathrm{l}^{-1}$ ), activated sludge treatment without nitrification (DOC of $11 \mathrm{mg} \mathrm{l}^{-1}$ ), or moving-bed bioreactor treatment with full nitrification (DOC of 5, 7 and $8 \mathrm{mg}^{-1}$ ). PAC (10 mg $\mathrm{l}^{-1}$, triplicates, SORBOPOR ${ }^{\mathrm{TM}} \mathrm{MV}-125$, Envir Link SA, Switzerland) was added to the different types of wastewater and agitated at $140 \mathrm{rpm}$ for $24 \mathrm{~h}$ in the dark at $20^{\circ} \mathrm{C}$. 


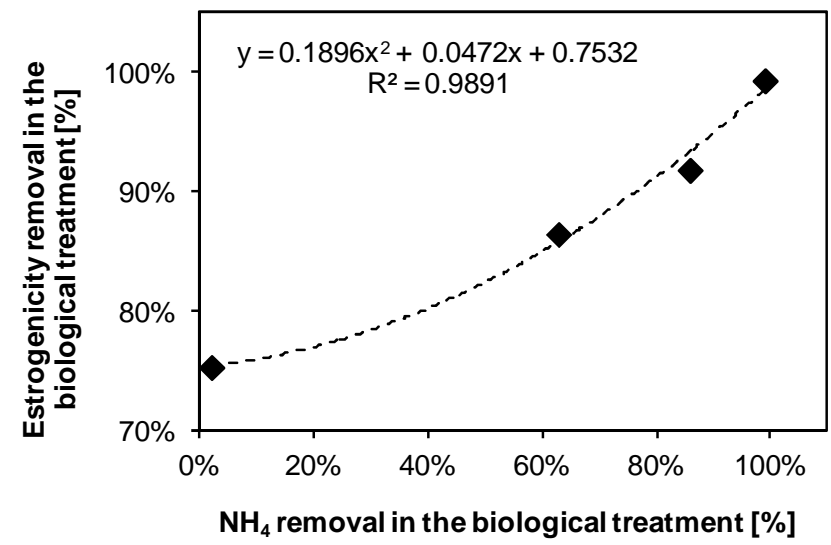

Figure S10. Estrogenic activity removal in the biological treatment (activated sludge or moving bed bioreactor) as a function of the level of nitrification $\left(\mathrm{NH}_{4}\right.$ removal). Estrogenic activity was measured with the YES on four 7-d composite samples in the influent and effluent of the biological treatment with various levels of nitrification. Dashed line: fitted quadratic trend line.

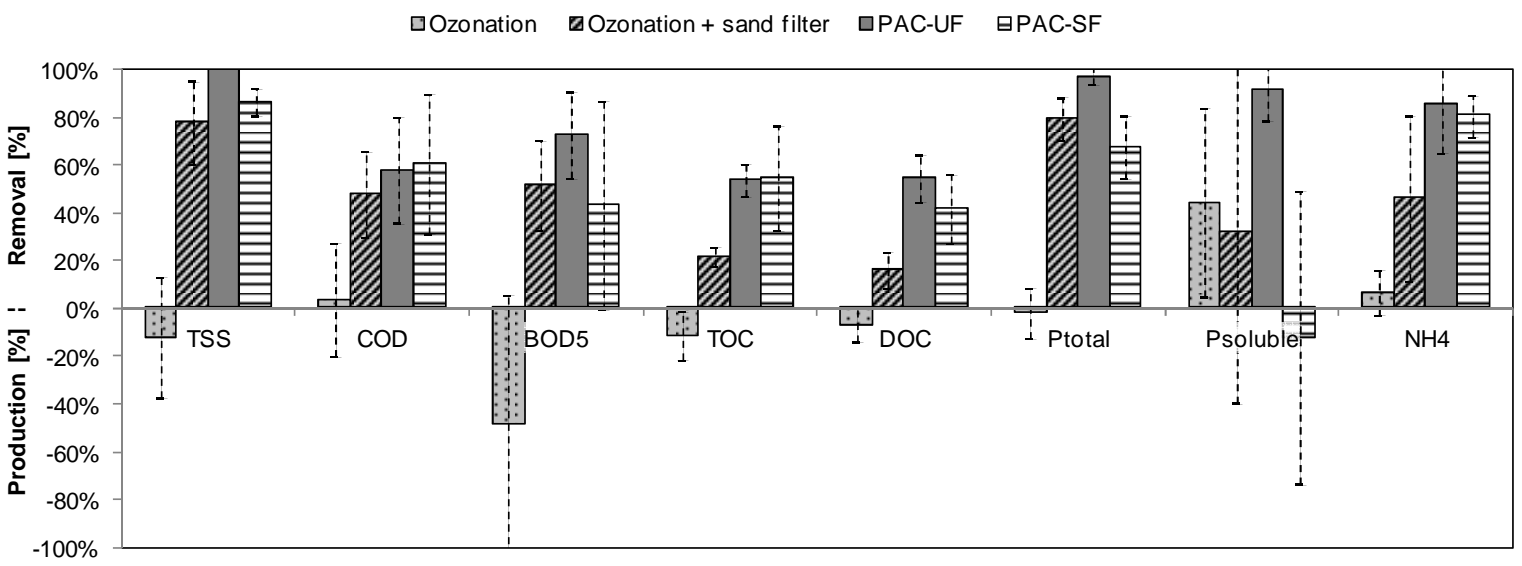

Figure S11. Removal of macropollutants with ozone, ozone/sand filter, PAC-UF and PAC-SF. Average and standard deviation of 14 (9 for PAC-SF) 24-h composite samples. Ozone dose of 3.8-7.0 $\mathrm{mg} \mathrm{O}_{3} \mathrm{l}^{-1}$, PAC dose of 10-20 $\mathrm{mg} \mathrm{l}^{-1}$, coagulant (for PAC-UF only): 5-15 $\mathrm{mg} \mathrm{FeCl}_{3} \mathrm{l}^{-1}$. TSS: total suspended solid, COD: chemical oxygen demand, $\mathrm{BOD}_{5}$ : 5-d biochemical oxygen demand, TOC: total organic carbon, DOC: dissolved organic carbon, $\mathrm{P}_{\text {total }}$ : total phosphorus, $\mathrm{P}_{\text {soluble }}$ : dissolved phosphorus, $\mathrm{NH}_{4}$ : ammonium. 
口Total viable bacteria (CFU/ml) घEscherichia coli (CFU/100 ml) 圈 Enterococci (CFU/100 ml)

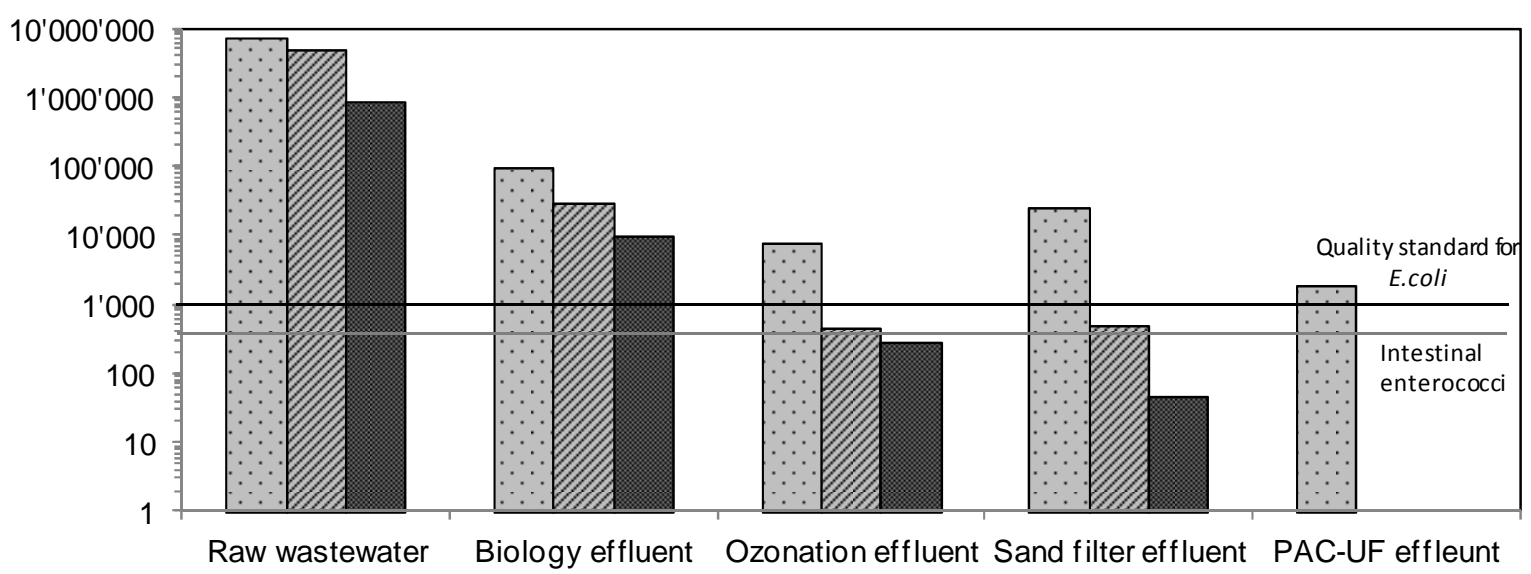

Figure S12. Influence of the treatments on the concentration of indicator bacteria in the effluent. Average of two campaigns (grab samples) with $6.9 \mathrm{mg} \mathrm{O}_{3} \mathrm{l}^{-1}$ or $20 \mathrm{mg} \mathrm{PAC}^{-1}$. European standards for good bathing water quality (Directive 2006/7/EC) are given for E. coli (1000 CFU/100 ml) and intestinal enterococci (400 CFU/100 $\mathrm{ml})$ as comparative values.

\section{References}

Escher BI, Bramaz N, Mueller JF, Quayle P, Rutishauser S, Vermeirssen ELM. Toxic equivalent concentrations (TEQs) for baseline toxicity and specific modes of action as a tool to improve interpretation of ecotoxicity testing of environmental samples. Journal of Environmental Monitoring 2008; 10: 612-621.

Escher BI, Baumgartner R, Koller M, Treyer K, Lienert J, McArdell CS. Environmental toxicology and risk assessment of pharmaceuticals from hospital wastewater. Water Research 2011; 45: 75-92.

Holbech H, Kinnberg K, Petersen GI, Jackson P, Hylland K, Norrgren L, et al. Detection of endocrine disrupters: Evaluation of a Fish Sexual Development Test (FSDT). Comparative Biochemistry and Physiology - C Toxicology and Pharmacology 2006; 144: 57-66.

Morasch B, Bonvin F, Reiser H, Grandjean D, De Alencastro LF, Perazzolo C, et al. Occurrence and fate of micropollutants in the Vidy Bay of Lake Geneva, Switzerland. Part II: Micropollutant removal between wastewater and raw drinking water. Environmental Toxicology and Chemistry 2010; 29: 1658-1668.

OECD. OECD Guideline for testing of chemicals 203: Fish, Acute Toxicity Test, 1992a. http://www.oecdilibrary.org/environment/test-no-203-fish-acute-toxicity-test_9789264069961-en, last accessed 5 February 2013.

OECD. OECD Guideline for testing of chemicals 210: Fish, Early-life Stage Toxicity Test, $1992 \mathrm{~b}$. http://www.oecd-ilibrary.org/environment/test-no-210-fish-early-life-stage-toxicitytest_9789264070103-en, last accessed 5 February 2013.

Reungoat J, Escher BI, Macova M, Argaud FX, Gernjak W, Keller J. Ozonation and biological activated carbon filtration of wastewater treatment plant effluents. Water Research 2012; 46: 863-872.

Routledge EJ, Sumpter JP. Estrogenic activity of surfactants and some of their degradation products assessed using a recombinant yeast screen. Environmental Toxicology and Chemistry 1996; 15: 241-248.

Schreiber U, Quayle P, Schmidt S, Escher BI, Mueller JF. Methodology and evaluation of a highly sensitive algae toxicity test based on multiwell chlorophyll fluorescence imaging. Biosensors and Bioelectronics 2007; 22: 2554-2563.

Stalter D, Magdeburg A, Weil M, Knacker T, Oehlmann J. Toxication or detoxication? In vivo toxicity assessment of ozonation as advanced wastewater treatment with the rainbow trout. Water Research 2010; 44: 439-448.

Schwarzenbach RP, Gschwend PM, Imboden DM. Environmental Organic Chemistry - Second edition. Hoboken, USA: John Wiley \& Sons, Inc., 2003. 